\title{
MÉTODO ALTADIR DE PLANEJAMENTO POPULAR EXPERIENCIADO NO PLANEJAMENTO ANUAL DO PET-ENFERMAGEM/UEM
}

\author{
Embert Luan Correa Pereira ${ }^{1}$ \\ Rebeca Iwankiw Lessa ${ }^{2}$ \\ Mariane Nayra Silva Romanini ${ }^{3}$ \\ Rafaela Ghiraldi Rocha ${ }^{4}$ \\ André Estevam Jaques ${ }^{5}$ \\ Vanessa Denardi Antoniassi Baldissera ${ }^{6}$
}

PEREIRA, E. L. C.; LESSA, R. I.; ROMANINI, M. N. S.; ROCHA, R. G.; JAQUES, A. E.; BALDISSERA, V. D. A. Método Altadir de planejamento popular experienciado no planejamento anual do Pet-enfermagem/Uem. Arq. Cienc. Saúde UNIPAR, Umuarama, v. 21, n. 3, p, 163-168, set./dez. 2017.

RESUMO: Este estudo trata-se do relato de experiência cujo objetivo é explanar o potencial educativo permeado pelo Método Altadir de Planejamento Popular no processo de planejamento anual das ações do grupo Enfermagem do Programa de Educação Tutorial. O grupo é constituído por doze alunos de Enfermagem, bolsistas do Programa: quatro da segunda série do curso; três da terceira série; cinco da quarta série; e uma tutora. O processo de planejamento das ações anuais do grupo aconteceu entre os meses de novembro de 2016 e janeiro de 2017, integrando a apresentação do método e a aplicação de suas etapas. Como resultado, obteve-se a experiência inovadora de o grupo utilizar um método participativo para planejar suas ações, visto que isso possibilitou a discussão coletiva, a corresponsabilização dos envolvidos para as situações-problemas concretas e a aprendizagem problematizada do planejamento. O método de planejamento utilizado foi considerado pertinente e exequível ao grupo e a experiência relatada infere sua possibilidade em ser adotado como forma de planejamento em realidades descentralizadas aliada à aprendizagem dialógica.

PALAVRAS-CHAVE: Educação Tutorial. Enfermagem. Planejamento Participativo.

\section{ALTADIR POPULATION PLANNING METHOD EXPERIENCED IN THE ANNUAL PET-NURSING/UEM PLANNING}

\begin{abstract}
This study is an experience report with the purpose of explaining the educational potential of the Altadir Population Planning Method (MAPP) in the annual planning process of the Nursing Group in the Tutorial Education Program of the State University of Maringá for 2017. The group is made up of twelve nursing students, program fellows - four in the second year of the course; three in the third year; five in the fourth year; and a professor. The planning process took place between November 2016 and January 2017, integrating the MAPP presentation and the implementation of its stages. An innovative experience resulted from the experience, with the group using a participative method to plan its actions. Such method allowed for collective discussion and the commitment of those involved, besides showing that the method can also be applied in diverse planning situations and reproduced in the daily academic and professional routines. In view of the above, it can be concluded that it was possible to identify MAPP as something applicable to the PET, and the reported experience infers that it is a possible strategy to be adopted as an effective form of planning, being also able to make teaching, research and extension inseparable. KEYWORDS: Nursing. Participative Planning. Tutorial Education.
\end{abstract}

Introdução

O Programa de Educação Tutorial (PET), de iniciativa do Ministério da Educação (MEC), possui por objetivo a formação acadêmica e social de excelência, complementar às atividades curriculares, permitindo a criticidade por meio do trabalho coletivo. Cada grupo do PET pode ser formado por até 12 alunos bolsistas e no máximo 6 não bolsistas, além de um professor tutor. O Fundo Nacional para o Desenvolvimento da Educação (FNDE) é o órgão de fomento do Programa em território nacional e a Secretaria de Educação Superior (SESu/MEC) seu órgão doutrinador (BRASIL, 2006).

Os projetos desenvolvidos pelo Programa, visam ao aprimoramento do método de ensino da Instituição, por meio de pesquisas que se referem à produção de conhecimentos e consequentemente, a extensão que retrata o campo profissionalizante, trabalhando assim de forma indissociável com a tríade: ensino, pesquisa e extensão (ARANHA; MAGNONI; MIRANDA, 2013).
Para sustentar as atividades anuais propostas é necessário um planejamento anual como instrumento interno de gestão. Após sua realização, é enviado e avaliado pela pró-reitoria de ensino e pelo Comitê Local de Acompanhamento e Avaliação (CLAA) de cada Instituição de Ensino Superior (IES). A partir disso, as atividades planejadas passam a direcionar as atividades do grupo PET ao longo do ano (BRASIL, 2006).

O planejamento, portanto, é para o PET uma das competências necessárias para cumprir preceitos legais de seu funcionamento, mas também para a tomada de decisão. Para cumprir tais competências, o planejamento precisa surgir a partir da compreensão de uma situação-problema contextualizada, para que possam ser definidas hipóteses e soluções cabíveis (CECCON, 2013), exigindo um trabalho colaborativo e coletivo permeado pela interação e organização dos envolvidos.

Por considerar essas premissas do planejamento, o grupo PET-Enfermagem da Universidade Estadual de Ma-

DOI: 10.25110 /arqsaude.v21i3.2017.6218

${ }^{1}$ Acadêmico de Enfermagem, PET-Enfermagem, Universidade Estadual de Maringá (UEM);

${ }^{2}$ Acadêmica de Enfermagem, PET-Enfermagem, Universidade Estadual de Maringá (UEM);

${ }^{3}$ Acadêmica de Enfermagem, PET-Enfermagem, Universidade Estadual de Maringá (UEM);

${ }^{4}$ Acadêmica de Enfermagem, PET-Enfermagem, Universidade Estadual de Maringá (UEM);

${ }^{5}$ Doutor em ciências, Docente do Departamento de Enfermagem, Universidade Estadual de Maringá (UEM);

${ }^{6}$ Doutora em ciências, Docente do Departamento de Enfermagem, Tutora do PET-Enfermagem, Universidade Estadual de Maringá (UEM). 
ringá (UEM) entendeu que sua realização presumiria a utilização de referenciais teóricos e metodológicos, os quais permitiriam o embasamento científico para essa atividade de gestão interna, já galgando experiências de formação acadêmica fundamentadas nessa temática. Diferentemente da maneira que o grupo costumava realizar o planejamento anual, desprovida de fundamentação teórica e metodológica, entendeu-se que seria possível definir ações contextualizadas em problemas reais do grupo, frente aos objetivos instituídos ao PET pelo MEC, tornando o planejamento eficaz no sentido de atingir bons resultados.

São diversos os referenciais teórico-metodológicos existentes na literatura, mas para o contexto do PET seriam relevantes algum que contemplassem a participação ativa dos integrantes do grupo no planejamento. Na busca de tais referenciais teórico e metodológico, destacou-se o Método Altadir de Planejamento Popular (MAPP), por possibilitar uma prática de planejamento participativa e dialógica, transformadora e resolutiva, sobretudo por sua natureza participativa e colaborativa, indispensáveis ao trabalho do PET. Também foi considerado um método oportuno por tratar-se de um referencial adotado no curso de Enfermagem da UEM, como componente do estágio curricular supervisionado (BALDISSERA; GÓES, 2012).

Para além desses aspectos, a aplicabilidade do método apresentou-se inovadora, visto que não foi encontrada publicação alguma que apontasse sua utilização em planejamento de grupos PET.

$O$ MAPP pareceu atender às exigências do MEC quanto às estratégias de planejamento de um grupo PET, mas restava, entretanto, construir sua experiência de forma criteriosa, tal qual feito e relatado por esse trabalho.

O presente estudo, portanto, tem a finalidade de relatar o potencial educativo permeado pelo Método Altadir de Planejamento Popular no processo de planejamento anual das ações do grupo Enfermagem de um Programa de Educação Tutorial.

\section{Metodologia}

Relato de experiência do grupo PET-Enfermagem da UEM, sobre a utilização MAPP, no processo de planejamento anual das atividades do PET-Enfermagem para o ano de 2017, destacando seu potencial educativo permeado pela reflexão da prática, no movimento da ação-reflexão-ação (FREIRE, 2011). Cumpre destacar que esse processo de planejamento anual do PET-Enfermagem aconteceu entre os meses de novembro de 2016 e janeiro de 2017, por meio de discussões coletivas em sete reuniões de trabalho, integrando a aproximação teórica com o MAPP e a aplicação de suas etapas.

O MAPP é um método de planejamento simples e criativo que pode ser utilizado em nível local e descentralizado em distintos contextos, como é no trabalho do grupo PET-Enfermagem da UEM que detém autonomia e descentralização em relação ao programa que é de direcionamento nacional. O MAPP tem por objetivo viabilizar discussões coletivas de problemáticas e possíveis soluções para elas, por meio da organização de um plano de ação, favorecendo a corresponsabilização dos envolvidos, tornando-os atores ativos desse processo (BARRETO; MATHIAS, 2013). Assim, o MAPP atua como transformador, proporcionando a resolutividade dos problemas locais. Por esse objetivo se concretiza seu potencial educativo dialógico ao possibilitar que a prática seja reconhecida, pensada, repensada e recriada (FREIRE, 2011).

O MAPP foi inicialmente descrito por seu proponente em 15 passos (SANTANA, 1997; TANCREDI; BARRIOS; FERREIRA, 1998): seleção de problemas; descrição do problema; explicação do problema; desenho da situação objetivo; seleção de nós críticos; desenho das demandas e operações; definição das responsabilidades; definição de responsáveis pelas demandas de operação; avaliação e cálculo dos recursos necessários; identificação de atores sociais frente ao plano; identificação de recursos críticos para desenvolver as operações; identificação dos atores que controlam os recursos; seleção de trajetórias; análise da vulnerabilidade do plano; desenho do sistema de prestação de contas (NASCIMENTO; SILVA; GOYATÁ, 2013).

Estes 15 passos do MAPP foram, posteriormente, resumidos em seis: seleção de problemas; descrição dos problemas; explicação dos problemas; formulação da situação objetivo; seleção de frentes de ataque; e desenho de operações e demandas (ASSIS; PEREIRA; MISHIMA, 1997; SANTANA, 1997), atualmente assim utilizado por sua praticidade e aplicabilidade no cenário do planejamento em saúde altamente descentralizado (BALDISSERA; GÓES, 2012; BARRETO; MATHIAS, 2013). Essa versão resumida do MAPP foi utilizada pelo grupo PET-Enfermagem na experiência aqui relatada.

\section{Relato de experiência}

\section{A aproximação e preparo do grupo para utilizar o MAPP}

A aproximação e preparo do grupo PET-Enfermagem com o MAPP se deu em quatro reuniões semanais, com o auxílio de dois petianos egressos do PET-Enfermagem. Foi realizado, na primeira reunião, a apresentação do MAPP e sua aplicação. Para essa atividade, a tutora e os alunos egressos tiveram papéis fundamentais, trazendo experiências reais para que os demais pudessem conhecê-las e problematizá-las em sua concretude (FREIRE, 2016). Tal feito favoreceu a corresponsabilização e participação efetiva no processo de planejamento, por melhor entender o papel individual e coletivo que seria necessário no contexto do PET-Enfermagem, uma vez que o dialogar suas perspectivas, de forma autêntica, seria decisivo para transformar a realidade por meio de novos aprendizados construídos coletivamente (FREIRE, 2016).

O MAPP, por ser um planejamento participativo, exige a clarificação de seu percurso, sendo este o momento oportuno para identificar os nós críticos do planejamento normativo, até então desempenhado pelo PET-Enfermagem, e as mudanças essenciais para transformar tal prática. Essa discussão coletiva da aplicabilidade do MAPP e de suas vantagens ao planejamento normativo, no que se refere ao nível de envolvimento dos participantes, funcionou como alavanca para que o grupo pudesse sair de "sua zona de conforto" e construir, de modo corresponsável, um planejamento de ações alinhado com a realidade local (VAZ et al. 2016).

Por seu caráter integrador, apreendeu-se que o planejamento participativo, para além do resultado pontual de gerar um plano coletivo, também se tornou um momento de aprendizagem, por desvelar novas possibilidades de planeja- 
mento e de trabalho em equipe. De acordo com Freire (2016) o processo de ensinar e aprender se dá na comunhão das pessoas, por meio do diálogo e da participação efetiva, tal qual esse momento se fez para os petianos.

\section{Os passos do MAPP}

\section{Primeira Etapa: seleção de problemas}

$\mathrm{Na}$ reunião seguinte, com a presença de todos os envolvidos, foi elaborada uma lista contendo as principais situações-problemas do PET-Enfermagem, cujo planejamento de ações recairia. . Para cada situação-problema elencada, foi atribuído valor, interesse e pontuação, por negociação coletiva e consenso, tal qual preconiza o MAPP (TANCREDI; BARRIOS; FERREIRA, 1998; TONI; SALERNO; BERTINI, 2008). As situações-problemas com maior valor (alto), interesse positivo e melhor pontuação, numa escala de zero a 10, por consenso coletivo, devem desencadear o plano de ações (NASCIMENTO; SILVA; GOYATÁ, 2013).

Seguindo esses pressupostos, duas situações-problemas foram eleitas nesta etapa: 1) Pouca competência e habilidades dos petianos para a escrita científica; 2) Falta clareza nas normas e regras para condução das ações do grupo PET-Enfermagem. Ambas situações-problemas tiveram, na ponderação do grupo, valor alto, interesse positivo e pontuação máxima 10.

Destaca-se que as escolhas supracitadas foram balizadas pelas situações-limites e atos-limites desvelados pelo grupo (FREIRE, 2016). Assim, diante da reflexão que fizeram acerca das limitações na escrita científica, codificaram essa situação pela escassa produção científica e escolheram avançar nessa competência como ato-limite (FREIRE, 2016) para superar esse obstáculo. De igual importância destacada pelo grupo, foi apontada a ausência de normas e regras que orientassem as atividades e ações do grupo PET-Enfermagem para um andamento mais satisfatório, desvelando o trabalho colaborativo inerente à clarificação de papéis (SILVA, et al., 2015) que era situação frágil ao grupo na perspectiva dos petianos.

A respeito desse processo coletivo de definição das situações-problemas, argumenta-se que permite clareza das situações concretas que merecem um planejamento de ações e, ao mesmo tempo, favorece a corresponsabilização dos envolvidos porque suscita o sentimento de pertencimento (BALDISSERA; GOES, 2012). Não obstante, favorece aprendizado por instaurar a reflexão coletiva pautada nas situações concretas (BATISTA, 2008).

Os petianos envolvidos afirmaram satisfação com esse momento do planejamento, pelo fato de discutirem e decidirem, coletivamente, pelas situações cotidianas que deveriam mobilizá-los para resoluções, concretizando um momento educativo e dialógico que, além de ponto inicial do MAPP, foi espaço de descodificação da realidade concreta, revelada como impulso para aprender mais e fazer mais (FREIRE, 2016).

Segunda e Terceira etapas: Descrição e explicação do problema - árvore explicativa/árvore de problema

De acordo com o referencial adotado, essas etapas destinavam-se descrever as situações-problema selecionadas na etapa anterior, identificando seus descritores e indicadores. Também, explicá-las por meio da identificação de suas causas e consequências. Para tanto, escolheu-se uma das situações-problemas eleitas na etapa anterior para descrevê-la quanto aos descritores e indicadores e elencar suas causas e consequências. $\mathrm{O}$ mesmo processo foi realizado com a outra situação-problema.

Para a situação-problema 1) Pouca competência e habilidades dos petianos para a escrita científica, foram definidos os seguintes indicadores: não existem publicações científicas recentes de autoria do grupo PET- Enfermagem. Como descritores foram apontados: há limitação por parte dos integrantes do grupo PET Enfermagem para a escrita científica.

A situação-problema 2) Falta clareza nas normas e regras para condução das ações do grupo PET-Enfermagem, teve como indicadores: falta de comprometimento em seguir o que é pré-estabelecido, falta de pontualidade, ausência em reuniões grupais sem justificativas ou sem justificativas plausíveis e há pouca participação efetiva dos integrantes do grupo em eventos; e como descritores apontados: pouca resposta positiva nas tentativas de estabelecimento de regras no grupo; falta de assiduidade, de pontualidade e de comprometimento de tarefas; pequena participação dos integrantes do PET-Enfermagem em eventos internos e externos.

Para Tancredi; Barrios e Ferreira (1998) a definição de descritores e indicadores facilitam o reconhecimento claro do problema, no contexto em que acontece. Por sua vez, identificar causas e consequências direcionam os planos de ação, no sentido de que ações exitosas devem ser dirigidas para as causas dos problemas que impactarão nas suas consequências. A esse mesmo respeito observa-se que os descritores são objetivos mensuráveis, o que permite criar indicadores e avaliar, ao final, o impacto do planejamento (TONI; SALERNO; BERTINI, 2008).

Embora sejam essas etapas normativas do MAPP que podem ser entendidas, numa primeira aproximação, como contraditórias ao diálogo, é importante esclarecer que não são; pelo contrário, permitem desvelar a situação concreta (FREIRE, 2016), buscando explicações causais e definindo critérios de alcance. Nessa direção, codificar, descodificar e desvelar criticamente por meio da problematização (FREIRE, 2016), tal como essa etapa do MAPP, é um caminho que concretiza o caráter dialógico freiriano, refletindo seu potencial educativo no ato de planejar.

Essas etapas representaram um passo importante para que, ao apreender as explicações do problema, fosse inspirada a consciência crítica da realidade coletiva (FREIRE, 2016) para que dela se tomasse consciência com finalidade de modificá-la por ações agora não mais alienadas, mas providas de intencionalidade material. A busca por explicações, fundadas na realidade de quem as vive, é imperativa para o aprendizado mediatizado pelo mundo (FREIRE, 2016), uma vez que a consciência desvelada e dialogada por seus pares impulsiona para novas práticas.

Essa etapa do MAPP, portanto, foi decisiva para o processo de planejamento tanto quanto para reconhecer os problemas em direção a sua superação, o que indiscutivelmente fundou em aprendizado coletivo.

\section{Quarta etapa: Formulação da situação objetivo}

Nesta etapa o MAPP sugere que os objetivos que podem ser alcançados sejam discutidos e, então, elaboradas 
formas de torná-los realizáveis. Para isso, avalia-se o prazo de sazonamento deste plano e assimilação das operações que podem contribuir para a mudança que se deseja alcançar, além de dimensionar o alcance e a natureza dessas operações.

A orientação teórica é partir da construção de uma "árvore da situação objetivo", apontando claramente o problema e os resultados esperados, para que os processos decisórios em relação ao objetivo possam levar em conta o tempo, o impacto das operações e por fim, comparar a situação-problema com aquela que se deseja alcançar (TANCREDI; BARRIOS; FERREIRA,1998; TONI; SALERNO; BERTINI, 2008).

Para a situação-problema 1) Pouca competência e habilidades dos petianos para a escrita científica, a situação-objetivo estabelecida foi preparar e desenvolver competências para a escrita científica. Na situação-problema 2) Falta clareza nas normas e regras para condução das ações do grupo PET-Enfermagem, a situação-objetivo elencada foi estabelecer pactuação para a definição e seguimento de regras indispensáveis ao bom andamento das atividades do grupo.

O trabalho entorno desta etapa exigiu que o grupo tivesse uma reflexão aprofundada, para assim, ajustar as operações e atingir as metas, além disso proporcionou maior clareza na visualização da estratégia. Ao agir dessa forma, instauraram a teoria a partir da prática, aglutinando a práxis centrada na ação-reflexão-ação (FREIRE, 2011; TEIXEIRA; TALAMONI; TOZONI-REIS, 2013) e, por isso, um momento de aprendizado emergiu da prática contextualizada e refletida.

\section{Quinta etapa: Seleção de frentes de ataque}

Nesta etapa os descritores dos problemas e dos resultados previstos foram definidos, permitindo a visualização do impacto e da possibilidade de ação, sobre as situações-problema, sendo entendido pelo grupo como importante etapa.

Para tanto, balizados pela árvore da situação-objetivo descrita na etapa anterior, o grupo definiu as causas dos problemas cujas operações, diretamente ou indiretamente, atacassem os problemas em busca de sua superação, para que pudessem ser tomadas decisões em relação às possibilidades de ações exequíveis e sua eleição para se pensar em ações concretas. Assim, as causas das situações-problemas foram eleitas para definição de operações. Para a situação-problema 1) Pouca competência e habilidades dos petianos para a escrita científica, definiram-se como causas a sobrecarga de atividades dos últimos anos assumida pelo grupo; a carga horária extensiva do curso de graduação; a produção científica não é atividade prevista anualmente no planejamento do grupo; falta preparo para a escrita científica; os integrantes do grupo não participam ou desenvolvem iniciação científica. Para a situação-problema 2) Falta clareza nas normas e regras para condução das ações do grupo PET-Enfermagem, as causas elencadas foram ausência de normas e regras instituídas formalmente pelo grupo.

As possibilidades de operações elencadas nessa fase do MAPP, por meio da identificação coletiva de causas das situações-objetivo, são entendidas como pontapé transformador, pois atam os nós críticos e implicando em alterações para as causas dos reais problemas (TANCREDI; BARRIOS; FERREIRA, 1998).
Esse momento foi crucial para que o grupo se empoderasse coletivamente por meio do reconhecimento do problema e criticidade de ações que trariam impacto positivo, podendo superar os problemas, modelando o que se denomina de desvelamento crítico (FREIRE, 2016). Esse movimento coletivo de pensar em novos feitos balizados pelo real, agora criticamente entendido, conduz os envolvidos em direção ao inédito viável que, segundo Freire (2011) refere-se ao momento em que o fazer coletivo supera o habitual e concretiza a inovação. Inerente, portanto, a essa etapa do MAPP, foi o aprendizado coletivo que instaurou novos fazeres pelo ato concreto de repensar o antes feito.

\section{Sexta etapa: Desenhos de operações de demanda}

Nessa etapa foram elaboradas as operações, ou seja, os planos de intervenção, para os problemas apontados, além de identificar quem seriam os responsáveis e se necessitaríamos de apoio de outras instâncias do Departamento de Enfermagem e Universidade. As intervenções planejadas, relacionadas à situação-problema 1) Pouca competência e habilidades dos petianos para a escrita científica, foram: diminuir o número de reuniões presenciais; incluir no planejamento anual a produção científica; articular atividades do grupo com ensino-pesquisa-extensão; organizar e buscar formação em escrita científica; inserir os integrantes do projeto em grupos de pesquisa e fomentar iniciação científica nas atividades desenvolvidas pelo grupo. Para a situação-problema 2) Falta clareza nas normas e regras para condução das ações do grupo PET-Enfermagem, as operações previstas foram: estabelecer regras; redigir e revisar as regras para a condução de ações do grupo PET-Enfermagem, com ciência e concordância de todos, em cada planejamento anual; instituir mecanismos internos ao grupo para reconhecer, discutir e pactuar novas ações em caso de descumprimento de regras estabelecidas.

Para o PET-Enfermagem isso foi relevante por possibilitar o efetivo envolvimento com outros responsáveis, ampliando sua capacidade de decisão. A coordenação do conselho acadêmico da graduação e pós-graduação e chefia do departamento de enfermagem foram posteriormente consultados sob essas atribuições e concordaram plenamente com essa definição, fazendo-os parte do planejamento e das ações, como já está descrito no papel aglutinador do PET junto ao curso de graduação (BRASIL, 2006).

O sentimento de pertencimento a um grupo e sua afirmação por meio de pactuação é um caminho salutar para o trabalho coletivo, da mesma forma que imprescindível para alcançar mudanças. A transformação da prática pela reflexão sobre ela e pelo trabalho partilhado é, sem dúvida, uma forma de ensinar e aprender (CARVALHO, 2001).

Dessa maneira, o grupo PET entendeu que definir operações e compreender a governabilidade foi uma etapa do MAPP que trouxe aprendizado sobre gestão participativa, mas também implicou em possibilidade real de superação dos problemas vividos pelo grupo. Para além disso, essa etapa do MAPP oportunizou o aprendizado atitudinal e relacional, pois a negociação e a gestão de conflitos (CAMELO et al., 2016) precisou ser desenvolvida. 


\section{Avaliação do grupo quanto a experiência do MAPP}

Foi inovador utilizar um método participativo para planejar as ações do ano de 2017 pelo grupo PET-Enfermagem, visto que possibilitou a discussão em grupo e a corresponsabilização dos envolvidos com as situações e decisões (RODRIGUES et al., 2016).

O grupo PET-Enfermagem teve a experiência de utilizar um método que também pode ser aplicado em outras situações de planejamento e reproduzido em nosso cotidiano acadêmico e profissional (BALDISSERA; GÓES, 2012), como no planejamento interno de um programa.

Por fim, o planejamento das ações pautadas no MAPP, proporcionou aos envolvidos a aquisição de habilidades para o levantamento de problemas, seleção de prioridades, identificação de causas dos problemas, planejamento de ações para as causas identificadas e desenhos operações, além do aprimoramento de um olhar crítico, sendo possível assim, reconhecer a importância da utilização de referenciais teórico-metodológicos que envolvam o desenvolvimento de ações, para a elaboração de um planejamento (BARREIRO; MATHIAS, 2013), constituindo assim, uma experiência formativa.

\section{Conclusão}

Diante do exposto, foi possível identificar que o MAPP é um método aplicável ao PET, de fácil utilização, democrático e que exige a corresponsabilização, pelo fato de permitir a participação de todos os envolvidos na tomada de decisão, construindo o protagonismo deste processo. Sendo assim, oportunizou a aprendizagem mediada pela práxis (ação-reflexão-ação).

Dito isso, a experiência relatada infere que é um método possível de ser adotado como forma efetiva de planejamento e também uma forma de tornar ensino, pesquisa e extensão indissociáveis

\section{Referências}

ARANHA, A.S.; MAGNONI, A.F.; MIRANDA, G.V. Educação tutorial como ferramenta interdisciplinar no ensino-aprendizado de comunicação. In: Fórum Nacional de Professores de Jornalismo Escola Superior de Propaganda e Marketing, 4., 2015, São Paulo. Anais... São Paulo: UNESP, p. 20-28, 2015.

ASSIS, M. M. A.; PEREIRA, M. J. B.; MISHIMA, S. M. Planejamento em saúde: uma possibilidade de ação participativa. Rev. latino-am. enfermagem, Ribeirão PretoSP, v. 5, n. 4, p. 55-60, out. 1997.

BALDISSERA, V. D. A.; GÓES, H. L. F. O método altadir de planificação popular como instrumento de ensino da gerência em enfermagem. Investigación y educaciónem enfermeira. Universidad de Antioquia Medellín, Colombia, v. 30, n. 2 , p. $253-259,2012$.

BARRETO, M. S.; MATHIAS, T. A. F. Cuidado à gestante na atenção básica: relato de atividades em estágio curricular. Rev. da rede de enfermagem do Nordeste, v.14, n.3, p.639-648, 2013.
BATISTA, N. A.; BATISTA, S. H. S. S. A prática como eixo da aprendizagem na graduação médica. In PUCCINI, R. F.; SAMPAIO, L. O.; BATISTA, N. A. orgs. A formação médica na Unifesp: excelência e compromisso social. 1. ed. São Paulo: Editora Unifesp, 2008. p. 101-115.

\section{BRASIL, MINISTÉRIO DA EDUCAÇÃO. Manual de} orientações básicas - PET. Disponível em: $<$ http://portal. mec.gov.br/sesu/arquivos/pdf/petmanual.pdf $>$. Acesso em: 16 fev. 2017

CAMELO, S. H. H. et al. Competências profissionais e estratégias organizacionais de gerentes de enfermagem. Cienc. Enferm. v. 22, n. 1, p. 75-86, abr. 2016

CARVALHO, I. C. M. A invenção do Sujeito Ecológico: Sentidos e Trajetórias em Educação Ambiental. 2001, 349 f. p.239-241. Tese (doutorado) UFRGS. Porto AlegreRS, 2001.

CECCON, J. J. Os conhecimentos, habilidades e atitudes, necessários aos gestores em suas tomadas de decisões. In: Congresso virtual brasileiro de administração, 9, 2012.

Roraima. Anais... 2012. p. 20-25.

FERREIRA, A. S. Competências gerencias para unidades básicas do Sistema Único de Saúde. Ciência \& Saúde Coletiva, Rio de Janeiro-RJ, v. 9, n. 1, p. 69-76, 2004.

FREIRE, P. Pedagogia da autonomia: saberes necessários à prática educativa. 29. ed. São Paulo: Editora Paz e Terra, p. 54, 2004.

FREIRE, P. Educação como prática de liberdade. São Paulo: Editora Paz e Terra, p. 150, 2011.

FREIRE, P. Pedagogia do Oprimido. 60. ed. Rio de Janeiro: Editora Paz e Terra, p. 253, 2016.

NASCIMENTO, M. C.; SILVA, S. A.; GOYATÁ, S. L. T. Aplicação didática do método altadir de planejamento popular para estudantes de enfermagem. Rev. Enferm. Cent. O. Min, v. 3, n. 3, p. 891-898. 2013.

RODRIGUES, K. A. et al. Método Altadir de Planificação Popular (MAPP) e Planejamento em Saúde. In: Congresso Brasileiro dos Conselhos de Enfermagem-CBCENF, $16^{\circ}$., 2013. Vitória-ES. Anais... p. 50-55. 2013.

SANTANA, J. P. et al. Desenvolvimento gerencial de unidades básicas do Sistema Único de Saúde (SUS). 1997. 293 f. Brasília (DF): Organização Pan-americana de Saúde (OPAS); 1997.

SILVA, J. A. M. et al. Educação interprofissional e prática colaborativa na Atenção Primária à Saúde. Rev. Esc Enferm USP, v. 2, n. 49, p. 16-24.

TANCREDI, F. B.; BARRIOS, S. R. L.; FERREIRA, J. H. G. Planejamento em Saúde, v. 2. São Paulo: Faculdade de Saúde Pública da Universidade de São Paulo, 1998. 82p. 
TEIXEIRA, L. A.; TALAMONI, J. L. B.; TOZONI-REIS, M. F. C. A relação teoria e prática em projetos de educação ambiental desenvolvidos em um bairro de Bauru, Rev.

Ciência Educação. v. 19, n. 3 p. 657-676. 2013.

TONI, J.; SALERNO, G.; BERTINI, L. Uma abordagem estratégica no planejamento de grupos: o Método Altadir de Planejamento Popular - MAPP. In JACQUES, M. G. C. et al. org. Relações sociais e ética [online]. Rio de Janeiro: Centro Edelstein de Pesquisas Sociais. p. 140-150. 2008.

VAZ, A. C. N. et al. Utilização de matriz de intervenção como ferramenta para o planejamento participativo de ações em unidades básicas de saúde da coordenadoria regional de saúde oeste. In: XXX Congresso de Secretários Municipais de Saúde do Estado de São Paulo. São Paulo - SP, 2016.

Anais... p. 46-47. 2016.

Recebido em: 07/06/2017

Aceito em: 20/10/2017 